\title{
Aspectos epidemiológicos de um surto de babesiose cerebral em bovinos em zona livre de carrapato
}

\author{
Epidemiological aspects of an outbreak of cerebral babesiosis in cattle in tick free area
}

\author{
Ana Lucia Schild ${ }^{*}$ Jerônimo Lopes Ruas ${ }^{\mathrm{I}}$ Nara Amelia Farias ${ }^{\mathrm{II}}$ Fabiane Borelli Grecco ${ }^{\mathrm{I}}$ \\ Mauro Pereira Soares ${ }^{\mathrm{I}}$
}

\begin{abstract}
- NOTA-
RESUMO

Descrevem-se os aspectos epidemiológicos de um surto de babesiose cerebral ocorrido em bovinos no município de Santa Vitória do Palmar, RS em uma propriedade localizada geograficamente na Latitude $S 33^{\circ} 05^{\prime} 23^{\prime}$ e Longitude WO 5309'29", região considerada zona livre de Rhipicephalus (Boophilus) microplus. Em meados de novembro de 2007 foram transferidos para essa propriedade quatro touros, quatro novilhas e duas vacas provenientes do município de Minas do Leão,RS localizado geograficamente na Latitude S 30¹2’07”

four cows and two heifers originated from the municipality of Minas do Leão, RS, a tick endemic area, located at Latitude $S$ $30^{\circ} 12^{\prime} 07$ ' and Longitude WO $52^{\circ} 03^{\prime} 25^{\prime}$ ' were introduced in the herd. Fourty out of 393 adult cattle died. The first bovine died on January 19 and the last on March 2. The diagnosis of babesiosis was performed by the observation of gross lesions and numerous $\boldsymbol{B}$. bovis organisms in smears of the cerebral cortex. It is suggested that the mean temperatures between $23.2^{\circ} \mathrm{C}$ and $23.6^{\circ} \mathrm{C}$ and the relative humidity between $75.3 \%$ and $77.5^{\circ}$ observed in the period allowed the occurrence of a tick generation, which caused infection by $\boldsymbol{B}$. bovis in cattle without immunity.
\end{abstract} e Longitude WO 5203'25”. De um total de 393 animais, 40 bovinos adultos morreram no período entre 19 de janeiro e 2 de março de 2008. O diagnóstico foi realizado pela observação das lesões macroscópicas e pela presença de numerosas formas parasitárias de Babesia bovis em impressões de fragmentos do córtex telencefálico coradas por Giemsa, que foram enviados ao Laboratório Regional de Diagnóstico da Faculdade de Veterinária da UFPel (LRD). Sugere-se que o clima favorável com temperaturas médias entre $23,2^{\circ} \mathrm{C}$ e $23,6^{\circ} \mathrm{C}$ e umidade relativa do ar média entre $77,5^{\circ}$ e $75,3 \%$ observados no período determinaram a ocorrência de uma geração de carrapatos que ao infestarem e inocularem o agente em animais sem nenhuma imunidade contra o mesmo desencadearam o surto.

Palavras-chave: babesiose cerebral, Babesia bovis, doenças transmitidas por carrapato, Rhipicephalus (Boophilus) microplus, epidemiologia.

\section{ABSTRACT}

An outbreak of babesiosis by Babesia bovis is reported in cattle in the municipality of Santa Vitória do Palmar, considered a Rhipicephalus (Boophilus) microplus free area, in southern Brazil on a farm located at Latitude S $33^{\circ} 05^{\prime} 23^{\prime}$ " and Longitude WO 5309'29”. In mid November four bulls,
Key words: babesiosis, Babesia bovis, tick borne diseases, Rhipicephalus (Boophilus) microplus, epidemiology.

A babesiose cerebral é causada pelo hematozoário Babesia bovis transmitido pelo carrapato Rhipicephalus (Boophilus) microplus que se distribui entre as Latitudes $32^{\circ} \mathrm{Ne} 32^{\circ} \mathrm{S}$ (BRUM, 2001). Adoença causa perdas econômicas consideráveis na região Sul do Rio Grande do Sul, sendo a mais freqüente entre as enfermidades pertencentes ao complexo tristeza parasitária bovina (TPB) (ALMEIDA et al., 2006). A região Sul é considerada área de instabilidade enzoótica devido às condições climáticas que determinam períodos mais ou menos longos de ausência de infestação dos animais pelo carrapato e diminuição da imunidade dos animais ao agente responsável pela doença (FARIAS, 2007). Nos municípios de Chuí e Santa Vitória do Palmar, que se encontram ao sul do paralelo $32^{\circ} \mathrm{S}$ (Figura 1) a doença não ocorre e a região é

'Laboratório Regional de Diagnóstico, Faculdade de Veterinária, Universidade Federal de Pelotas (UFPel,) Campus Universitário, s/n, 96010-900, Pelotas, RS, Brasil. E-mail: alschild@terra.com.br. *Autor para correspondência.

IIDepartamento de Microbiologia e Parasitologia, Instituto de Biologia, UFPel, Pelotas, RS, Brasil. 


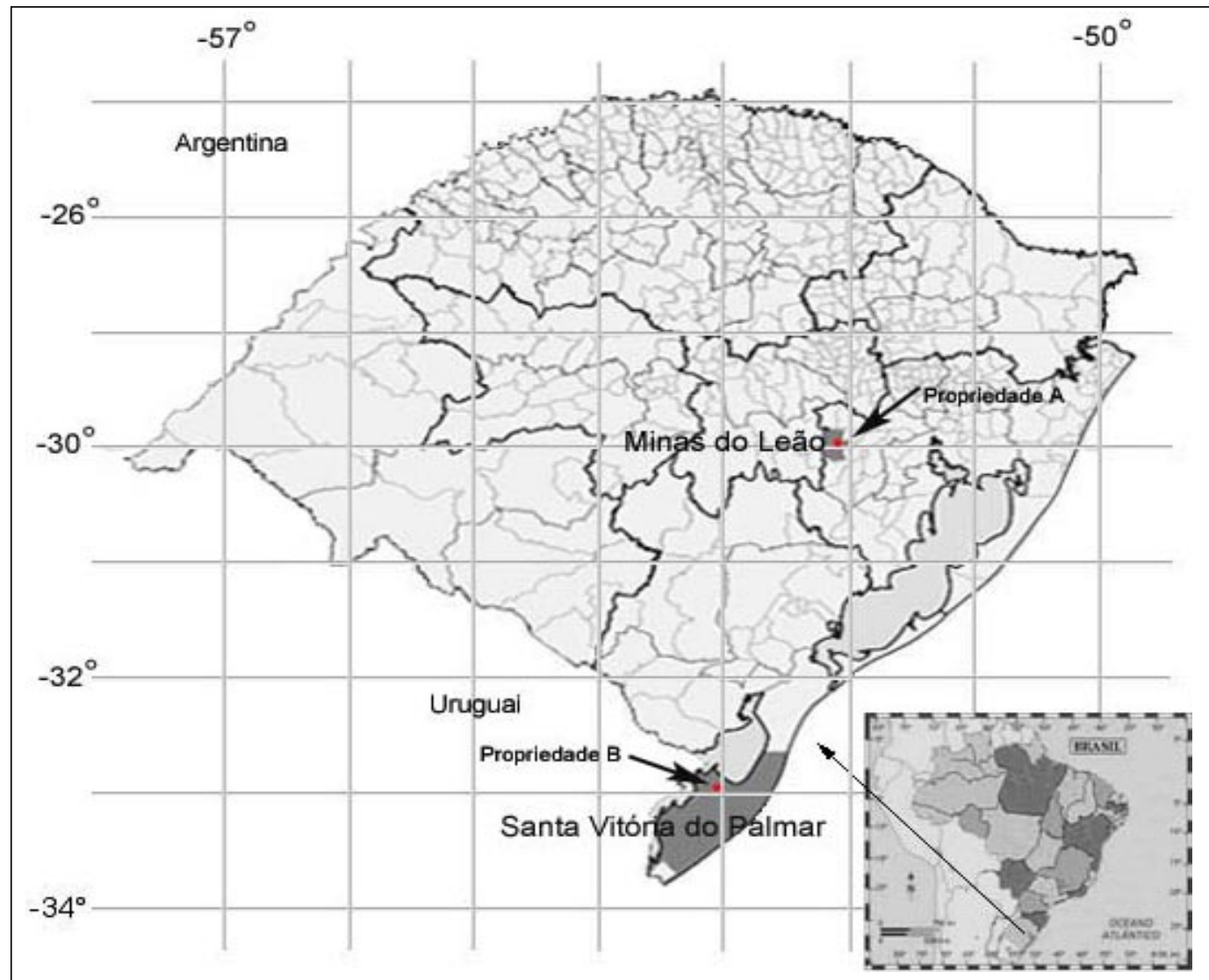

Figura 1 - Surto de babesiose cerebral em bovinos em zona livre de carrapato. Mapa do Rio Grande do Sul mostrando a localização da propriedade A, origem dos bovinos, e propriedade B onde ocorreu o surto.

considerada área livre. Nessas áreas todos os animais são susceptíveis e a doença pode ocorrer se houver entrada acidental de carrapatos em períodos de clima favorável (FARIAS, 2007).

O objetivo deste trabalho foi descrever um surto de babesiose cerebral observado em bovinos em uma propriedade do município de Santa Vitória do Palmar, zona livre da presença do carrapato, discutindose os fatores epidemiológicos que provavelmente levaram a sua ocorrência.

A propriedade onde ocorreu o surto (Propriedade B) está localizada geograficamente na Latitude S 3305’23”' e Longitude WO 5309'29”. Nessa propriedade havia 393 bovinos de raça mista e idades variadas divididos em três lotes mantidos em potreiros separados. No lote 1 havia 133 vacas de cria, três delas provenientes de uma propriedade (Propriedade A) localizada na Latitude S 30¹2’07 e Longitude WO 5203’25” no município de Minas do Leão, RS, considerado área endêmica para TPB (Figura 1), 125 bezerros desmamados entre machos e fêmeas e sete touros entre os quais dois também provenientes de
Minas do Leão. No lote 2 havia 26 novilhas de dois anos, três delas originárias de Minas do Leão e dois touros da mesma localidade. No lote 3 havia 47 vacas de descarte e 57 fêmeas de um ano de idade que não adoeceram. Todos os animais do município de Minas do Leão foram introduzidos na propriedade B em 14 de novembro de 2007. Antes de serem introduzidos na área , os bovinos haviam sido banhados aos 30, 15 e um dia antes de serem transportados para a propriedade. De acordo com funcionários havia carrapatos mortos dentro do caminhão de transporte e não foram observados carrapatos adultos nos bovinos. Nenhum desses bovinos foi afetado pela enfermidade. No dia 08/01/2008 todos os animais foram vacinados contra febre aftosa e receberam Ivomec Gold ${ }^{\circledR}$. Entre os dias 19 e 23 de janeiro morreram três novilhas do lote 2 . Entre 26 de janeiro e 8 de fevereiro morreram 31 vacas do lote 1 e entre o dia 28 de fevereiro e 2 de março morreram mais seis vacas do lote 1 . Em 28 de janeiro todos os animais foram vacinados para hemoglobinúria bacilar por ser esta a primeira suspeita da causa da mortalidade dos bovinos. Em 2 de março 
foram encontradas ninfas de $\boldsymbol{R}$. microplus em um bezerro que apresentou sinais clínicos da enfermidade e recuperou-se após o tratamento.

Não foram observados sinais clínicos nos bovinos que morreram. Fígado e baço inteiros, e urina de um bovino morto em 2 de fevereiro foram enviados ao LRD para diagnóstico. O fígado apresentava-se aumentado de volume e amarelado e a bile estava espessa; o baço estava aumentado e a urina tinha coloração escura. Foi descartada a suspeita de hemoglobinúria bacilar pela ausência da lesão característica no fígado. No dia seguinte, órgãos de outro bovino morto, incluindo o encéfalo, foram enviados ao LRD. Nesse material, além das lesões descritas acima, a coloração do córtex cerebral estava avermelhada (Figura 2) o que é um achado típico da babesiose por $\boldsymbol{B}$. bovis em bovinos (RODRIGUES et al., 2005). Em “claps” do encéfalo corados por Giemsa foram observadas numerosas formas parasitárias de B. bovis confirmando o diagnóstico. A média de temperatura nos meses de dezembro e janeiro na região foi de $23,2^{\circ} \mathrm{C}$ e $23,6^{\circ} \mathrm{C}$ respectivamente e a umidade relativa do ar variou de $77,5 \%$ a $75,3 \%$. O ciclo do carrapato quando em condições de temperatura e umidade ideais (temperatura de $27^{\circ} \mathrm{C}$ e umidade relativa do ar acima de 70\%) dura em torno de 55-60 dias. O carrapato tem uma fase de vida livre de aproximadamente 32 dias. A larva infectante sobe nos bovinos e em 4-5 dias origina a metalarva. As ninfas emergem no $8^{\circ}$ dia após a fixação no bovino e no $11^{\circ}$ dia originam as metaninfas que, 3-4 dias após, passam a machos e fêmeas (GONZALEZ, 2003). O período de incubação da babesiose varia de 7 a 10 dias e B. bovis é inoculada no bovino no período larval do carrapato (FARIAS, 2007). Considerando-se o período entre a chegada dos animais de Minas do Leão à propriedade em Santa Vitória do Palmar e o início do surto a hipótese da produção de uma nova geração de carrapatos devido às condições climáticas favoráveis é viável e provavelmente foi responsável pelo surto. Embora não tenham sido observados carrapatos adultos nos bovinos transportados, as formas imaturas são pequenas e podem não ser visualizadas. Outro fato que reforça essa hipótese é a não ocorrência de mortes no lote 3 no qual não foram introduzidos animais provenientes de Minas do Leão. Os bezerros desmamados que estavam no lote 1 não foram afetados o que pode ser explicado pelo fato de que animais de 710 meses são mais resistentes por apresentarem imunidade inespecífica (FARIAS, 2007). Os bovinos

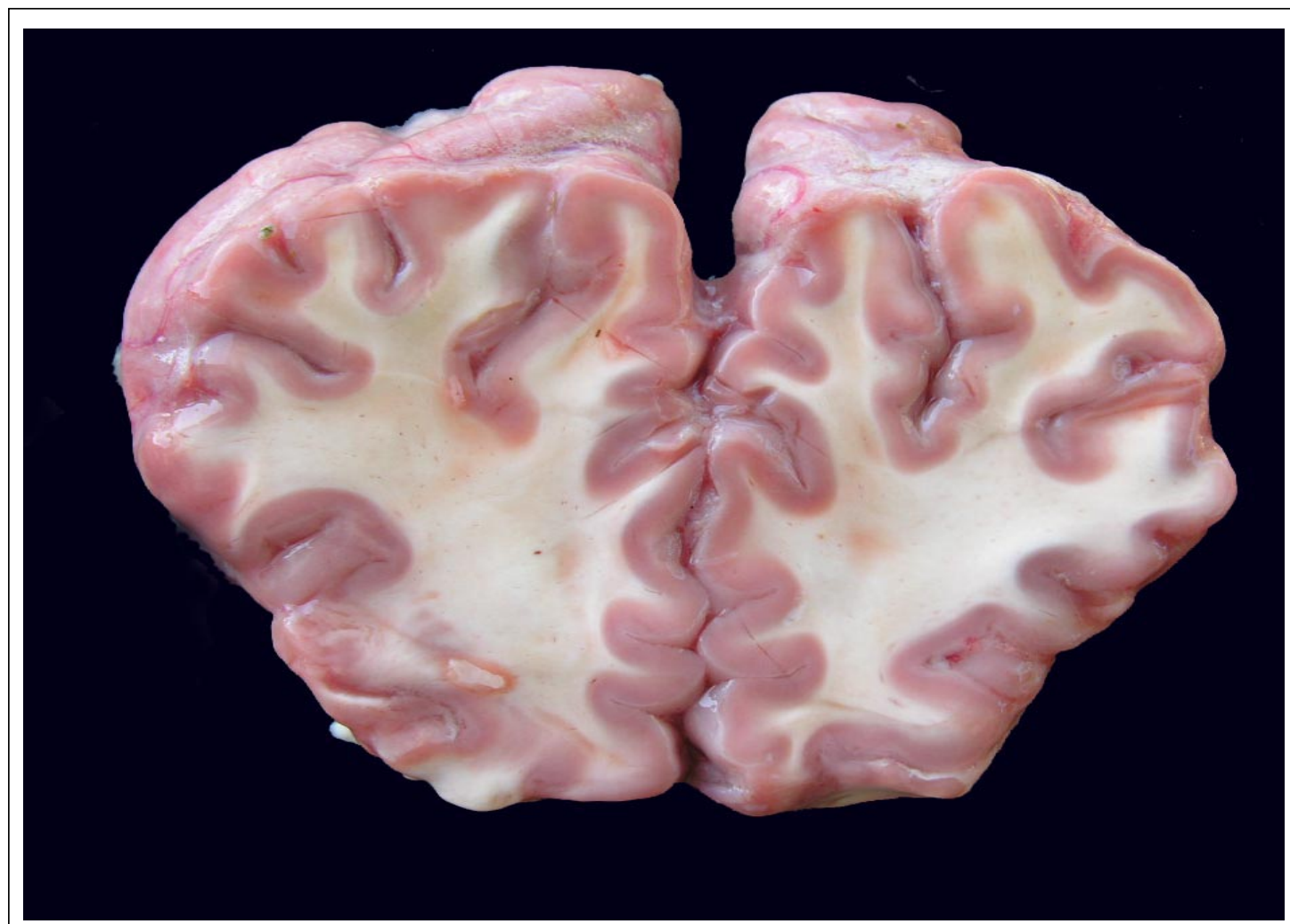

Figura 2 - Surto de babesiose cerebral em bovinos em zona livre de carrapato. Corte transversal do córtex telencefálico de um bovino afetado apresentando coloração avermelhada típica da doença. 
de Minas do Leão não adoeceram pela imunidade conferida pelo contato com o agente antes do transporte para Santa Vitória do Palmar. O fato de que os animais foram banhados antes do embarque sugere que, neste caso, o carrapaticida utilizado pode não ter tido $100 \%$ de eficácia permitindo a sobrevivência de alguns ínstares naturalmente mais resistentes como metalarvas, metaninfas e teleógenas. A sobrevivência de metalarvas sobre alguns bovinos além de serem dificilmente visualizadas devido ao tamanho reduzido $( \pm 2 \mathrm{~mm})$ provavelmente geraram larvas infestantes capazes de transmitir B. bovis no período em que ocorreram as mortes.

Por outro lado, a possibilidade da transmissão da doença pela agulha de vacinação e administração de medicamentos é pequena, uma vez que a inoculação do agente em todos os bovinos no mesmo dia (08/01) teria causado a mortalidade em um período curto de tempo (1-4 dias), não explicando a ocorrência das mortes até $02 / 03$, pois o período de incubação da babesiose varia de 7-10 dias. Além disso, o número de bovinos mortos não seria tão elevado. A transmissão de $\boldsymbol{B}$. bovis para bovinos ocorre exclusivamente pelo carrapato $R$. microplus. A transmissão mecânica por vetores biológicos, insetos hematófagos ou fômites ocorre na anaplasmose causada por Anaplasma marginale, outro componente do complexo TPB.

\section{REFERÊNCIAS}

ALMEIDA, M.B. et al. Tristeza parasitária bovina na região sul do Rio Grande do Sul: estudo retrospectivo de 1978 a 2005. Pesquisa Veterinária Brasileira, v.26, n.4, p.237-242, 2006.

BRUM, J.G. Carrapato dos bovinos. In: RIET-CORREA, F. et al. Doenças de ruminantes e eqüinos. 2.ed. São Paulo: Varela, 2001. V.2, cap.1, p.19-22.

FARIAS, N.A. Tristeza parasitária bovina. In: RIET-CORREA, F. et al. Doenças de ruminantes e eqüídeos. 3.ed. Santa Maria: Pallotti, 2007. V.1, cap.7, p.524-532.

GONZALEZ, J.C. O controle do carrapato do boi. 3.ed. Passo Fundo: UPF, 2003. 129p.

RODRIGUES, A. et al. Babesiose cerebral em bovinos: 20 casos. Ciência Rural, Santa Maria, v.35, n.1, p.121-135, 2005. 